\title{
Research on Information Management of Scientific Study Based on Resources and Capabilities
}

\author{
Ningning Yan \\ School of Management and Economics, Jingdezhen Ceramic Institute, Jiangxi Province, China \\ Isemail2008@163.com
}

Keywords: Scientific study; Resources and capabilities; Information management; Information organization structure; Information technology

\begin{abstract}
The resources and abilities of the general research results are applied to the informationization of scientific research management, can reveal the essence of informationization of scientific research management, found that the key lies in the cultivation of the scientific research management information system. This paper reviews the related literature information, the definition of the scientific research management information; research management information system will be divided into three aspects of scientific research management information technology, management information system of science research management information organization structure, innovation ability, and the detail. Research shows that the strategy of scientific research management information has become the cornerstone of lasting competitive advantage.
\end{abstract}

\section{Introduction}

The information construction of scientific research management is an important part of the management information and an important source of core competence. The theory of resources and capabilities into the scientific research management information, can reveal the essence of scientific research management information, especially the awareness of scientific research management information is the key to the ability of information technology.

In general, the organization informatization is through the application of modern information technology, communication, promote the sharing of information resources to meet the information needs of the organization, thus speeding up the development of the organization in different fields, and promote the process of digitalization construction. The information from the point of view of technology diffusion effect in the application of information technology in various fields and the technology system; economy refers to all areas of the use of modern information technology and equipment organization of various functional departments and activities, so as to improve the efficiency of the organization.

Peng Zhizhong believes that organizational information can be attributed to two characteristics of economic and management. Economy includes trade in service, external economy, sharing, timeliness, compatibility, diminishing marginal cost, increasing marginal utility, irreversibility, uncertainty of value and so on. Management performance for the operation of information technology, product or service design information, computer integrated manufacturing systems, etc. Study on syndrome Binghui showed that the organization informatization is in production, management and make full use of information technology. Zhangyu, Chenyu think that the information includes three aspects: production automation, flexibility and product intelligence; management integration; organic organization. These studies focus on the diffusion of information technology, but failed to reveal the essence of information technology. John Thorp puts forward the hierarchy theory of information needs. Information needs to include four aspects: the need for information infrastructure, the Internet and software needs, the need for knowledge capital management, the need for information warfare. The information construction of the organization should follow the order from low to high. Shao Hongyu pointed out that the information can change the organization and management, through the organizational process change and reengineering to improve efficiency and reduce costs, but this is only part of the information. In his 
view, starting from the theory of enterprise resources and ability, information should be to promote the sharing of information resources, so that the ability of information management has become the cornerstone of the organization's strategy and operation of the process.

Shao Hongyu also put forward the four stages of the development of organization information from the point of view of resource theory and ability theory: the first stage is the introduction of information technology; this stage is the introduction of information technology projects. The second stage is the stage of information standardization, the organization began to develop information management norms and mechanisms. The third stage is the diffusion of information technology, this stage began to appear on the comprehensive needs of information tools and resources. The fourth stage is the information innovation stage, this stage is the endogenous innovation stage, and information has been integrated into the whole process of organization. These four stages in accordance with the PDCA cycle operation, and constantly improve the organization's management and core competencies. The first and the two stage is to cultivate the information resources, the ability is still in the identification and germination; the third and four stages of information resources management, the ability to become the focus of management training.

\section{Scientific Research Management Information System Based on Resources and Capabilities}

Resources and capabilities generally include business resources and capabilities, organizational resources and capabilities, innovative resources and capabilities. Business resources and capabilities are divided into two categories: technology and process, organizational resources and capabilities are divided into the relationship and management control of the two categories, innovation resources and capabilities are divided into learning, technology innovation, and management innovation of the top three categories. Obviously, the main body of scientific research management information system should be scientific research business resources and capabilities (scientific research information resources and information technology), of course, and organization and innovation resources, ability is closely related. From the view of resource and capability system, through the analysis of the scientific research management information content and the relevant functional departments, we can research management information system is divided into three aspects: one is the scientific management of information technology, information technology is the research management department introduced from outside, relates to the innovation of scientific research resources research and technology, scientific research, including research management information infrastructure, information technology and information system of flexible learning ability.

The second is the scientific research management organization structure, it is a concrete manifestation of the scientific research management information technology diffusion and scientific management of information resource control in scientific management, including the scientific research management planning and control system, the ability of information diffusion technique. The third is the innovation ability of scientific research management information, it is the concrete manifestation of the scientific research process management and scientific research management business innovation, including the innovation of scientific research management information business, application ability, etc.

\section{Scientific Research Management Information Infrastructure}

The information infrastructure research originated from the computer hardware platform, especially from the perspective of connectivity and compatibility to analyze the functional characteristics of the information infrastructure.

This paper discusses how to construct information infrastructure and how to invest in these facilities, and classifies them according to their investment intensity, purpose and the relationship between them. On the basis of retaining the hardware platform of the information infrastructure, the service characteristics of the information infrastructure are emphasized.

The infrastructure of scientific research management information shall include the information construction in common computer software, hardware, information technology training, information 
security, information network and other content, but does not include specific business management system, such as scientific research management information system. Scientific research management information infrastructure is a part of information construction, is the main content of information resources construction. According to the requirements of scientific research management, and the analysis and evaluation of the investment and application level, the level and progress of the research will be determined. Some common indexes include the management of scientific research in computer ownership, network speed, database technology, scientific research management process informationization, scientific research resources integration degree to reflect the scientific research management level. However, this general evaluation index is not easy to unify the standard, but also for the scientific research management, its hardware and software investment, can not objectively and scientifically reflect the level of scientific research management information construction. The construction of scientific research management information is different from the general enterprise information construction, it is necessary to measure the level of the construction of the information infrastructure of the scientific research management. We can use knowledge management and information theory to evaluate and analyze the two aspects of scientific research management information infrastructure, which are the sharing degree of scientific research information and the service level of scientific research management.

First, the description of scientific research information sharing. The degree of scientific research information sharing can be analyzed from two aspects of research information sharing. The time characteristic of scientific research information sharing means that sharing can occur at any point in time, rather than at a specific point in time. The spatial characteristics of scientific research information sharing means that information infrastructure can provide information sharing services directly and automatically at different locations. This space from different locations of different research departments to any person, any place, as well as its higher authorities, support from the traditional information transfer to complex information systems applications.

Second, the level of scientific research management services. The service level of scientific research management can be reflected from the quantity, depth and effect of service. The quantity and effect of scientific research management services can get directly from the on scientific and technical research projects, management services and evaluation; scientific research management service depth mainly for the basic level of service management and functional management services. The basic level of management services is to provide some of the functions of the non-mandatory services, and functional management services is a relatively strong mandatory service. In reality, cannot provide all types of information infrastructure, different information infrastructure is not the same. Therefore, it is necessary to strengthen the management of information and provide the communication, application system and standard interface. Overall, the number, depth and effectiveness of information infrastructure services provided by research institutions, reflecting the ability of different information infrastructure management research.

\section{Scientific Research Management Information Learning Ability}

The information management of scientific research management is mainly the responsibility of scientific research and related management departments. The main task of information learning is to transfer knowledge from inside and outside to inside, and realize knowledge transfer, knowledge dissemination and knowledge diffusion. The information technology leader outside software producers, software sales, information technology and communication software enterprises mainly rely on the information technology feasibility scheme, software training and software consulting activities. The dissemination of scientific research information mainly depends on the training of the information department, and it is the key management of the scientific research management project in the relevant business departments.

Scientific research management information learning ability cultivation: one is the need to pay attention to the scientific research management departments should establish information learning process, the scientific research management and business sectors have become the carrier of knowledge and information, the information obtained to accumulate knowledge continuously. The cultivation of 
scientific research management information learning ability should not only actively promote individual learning, but also actively promote organizational learning, so that even if the core members of scientific research management information in the project can also leave, to reconstruct the information flow reconstruction through organizational learning. Information strategy should be regarded as the core strategy, the training of information technology and information technology as a regular behavior. Two is to actively construct information learning atmosphere. Only in a certain atmosphere can we promote the transfer, formation and application of knowledge. Is a knowledge intensive organization, was organized by different units and the formation of unique knowledge entities, each individual organizational unit in different environment, so the different organizational units of the knowledge situation is not the same, the knowledge innovation and application ability is also different. In essence, the knowledge context, the assignment of knowledge structure, the organization information system, the management system of control and innovation, and the individual skill and knowledge are the decisive factors of knowledge content, structure and knowledge creation. In recent years, the application of multimedia has promoted the improvement of the learning situation of the organization and individual. The interactive teaching is also becoming more and more popular.

\section{Strategic Planning and Control System of Scientific Research Management Information}

The strategic planning of scientific research management information is the focus of information control, is to study the impact of scientific research on the flow of scientific research, information technology to ensure the realization of scientific research business requirements.

The scientific research management information strategy planning is a broad concept, should include four meanings: one is the research of information resource planning, scientific research information is the core of scientific research management and information technology to implement the fundamental, is the information planning objectives; two is the scientific research information strategic planning, strategy is a long-term programme of action, the current research strategy is often a strategy that is the function of strategy; three is the scientific research information system planning, scientific research information system is the main means to realize informatization, its planning should be consistent with the development strategy; four is the research of information technology planning, scientific research and information technology is a scientific research information system security and support is mainly based on the research of information infrastructure design.

Research on information resource planning should be based on the information system planning, but also has its own characteristics, liquidity control scope, it should include scientific research information resources research information resources attributes and scientific information resources. The flow control of scientific research information resources is the control of the flow path and the authority in the scientific research management process. It should be noted that, if the inclusion of innovative activities or processes, research information often need to form a redundant, resulting in the management of scientific research information management loopholes, can be combined with other measures to prevent.

The starting point of scientific research management information resource planning as information strategic planning, strategic planning for information but also focus on research into the management of information resources and information technology research changes impact on the management, from the management, that includes management process change and organizational change, this is one of the mutual influence and mutual restriction strategy the organization is the key elements of internal relations, scientific research and related business processes, information management etc..

The basic steps of scientific research management information strategy planning and control system include: first analysis of the scientific research management information technology for improving the quantity, quality, type of scientific research management information, and analyzes its influence on the management mode and strategy; secondly, to analyze the influence of the development strategy of the scientific research management organization structure and business process from the global scientific research the angle of the information to determine the scientific process and organization, scientific research management system proposed by scientific research information flow as the core; third, the 
planning needs of the scientific research management information system, to determine the scientific management information system management strategy; finally, analyze information needs, and ultimately determine the implementation of scientific research management information technology.

The diffusion ability of scientific research management information is an integral part of knowledge diffusion ability. The power of knowledge diffusion comes from the competition, the manager's ability, the organization efficiency, and so on. The main obstacles are the potential difference of knowledge, the cultural difference and the over protection of the core knowledge. The diffusion of knowledge is helpful to promote the concept of value and realize the value maximization of knowledge innovation. Due to the existence of the real obstacles, knowledge diffusion needs to realize the management, especially the information innovation, to promote the integration and application of knowledge. Similarly, the cultivation of scientific research management information diffusion ability is a long process, scientific research management information diffusion ability is the comprehensive embodiment of quality information learning ability and innovation ability, is closely related with the ability of organization and culture of scientific research.

To sum up, the resources and capacity related research and application to the management of scientific research information, redefined the concept of scientific research management information, and the scientific research management information system based on the resources and capabilities are discussed. The scientific research management information is the process of making use of the advanced information technology to make the scientific research resources become the strategic resources. Scientific research management should be based on modern information technology, fully tap the scientific research information resources, build efficient information platform to promote scientific research management and standardization.

\section{Acknowledgement}

This work was supported by the research subject of teaching reform in colleges and universities of Jiangxi province (JXJG-16-11-22/ JXJG-15-11-9).

\section{References}

[1] Weill,P. The relationship between investment in information technology and firm performance: a study of the value manufacturing sector. Information systems research, Vol.3.2012, pp.307-331.

[2] Binghui Hou. Information technology leadership handbook. Beijing press, 2015.

[3] Zhizong Peng. Research on value added process of manufacturing enterprises based on information technology. School of management, Shanghai Jiao Tong University, 2012.

[4] John Thorp. The Information Paradox: Reality the Business Benefits of Information Technology. McGraw-Hill Press, 1999.

[5] Haifeng Li. Research on knowledge sharing in science and technology project management. School of management, Dalian University of Technology, 2010. 